\title{
Study on the Data analysis of the Camshaft Measuring Systems
}

\author{
Yuhua Wang ${ }^{1}$, Xiao Wang ${ }^{2}$ \\ 1,2 Beijing Institute of Technology Aerospace Test, Beijing, 100074 \\ 346591653@163.com
}

KEYWORDS: Data Analysis; $C_{g}$; Measurement of the Camshaft

\begin{abstract}
The accuracy of the camshaft directly impact the noise, dynamic performance and economy overall performance of automobile engine. This paper will measure the repeatability of the current index value $C_{g}$ of automotive components testing equipment corresponding analysis and give a set of the integrated measuring instrument data developed by camshaft actual measurement and develop indicators to verify the instrument reproducibility.
\end{abstract}

\section{Introduction}

Camshaft is one of five core automobile engine parts, precision camshaft directly affect noise, dynamic performance and economy overall performance of automobile engine.

According to the design requirements of modern instrumentation, measurement error random error should be accounted for the major part. Therefore, in assessing a (kind of) detection device, revealing random error associated with repeatability, reproducibility of these statistical properties are often the focus as the evaluation.

This paper will present a measure of the repeatability index value $C_{g}$ of automotive components testing equipment corresponding analysis, and given a set using the integrated measuring instrument developed by the camshaft actual measurement data, for the development of indicators to verify the instrument reproducibility.

\section{Meaning Measurement Capability Index Values $C_{g}$}

German auto industry from production reality, the repeatability factor reflects the error detecting device itself a prime location on the proposed measurement capability index $C_{g}$ assessment method.

During repetitive test, if the sample $n \geq 50$, thus obtaining the actual standard deviation $C_{g}$, and further obtain the measurement capability index, in order to make assessment of the equipment, its high precision and reliability, which is why, in August 1999 to develop the guidance document "Measurement system capability", using the measurement capability index $C_{g}$ of the assessment methods. 


$$
C_{g}=\frac{0.2 T}{\Delta M}
$$

Wherein $T$ is the tolerance measured coefficient distribution and $\Delta M$ is in the range of outcomes.

If the measurement errors are normally distributed, then there

$$
C_{g}=\frac{0.2 T}{2 k g s}
$$

Where $\mathrm{s}$ is the experimental standard deviation of available well known Bessel obtained from the formula. $k g$ Represents a confidence probability $\mathrm{P}$ of the confidence interval half-width, $\mathrm{k}$ is called the confidence factor, and $\mathrm{P}$ reflects the implementation of a measurement falls degree intervals may depend, such as when $k=3$, that is $P=0.99973,99.73 \%$.

That takes $3 \mathrm{k}$. The standard further made the following specific instructions: The acceptance of a new detection device, if the workpiece tolerance parameters $T \geq 10 \mu \mathrm{m}$, it is necessary to ensure that $C_{g} \geq 2$, if necessary assurance $T<10 \mu \mathrm{m}$. An additional conditions specified above $C_{g} \geq 1.33$, it is carrying out repetitive testing process, the number of measurements $n$ must be greater than or equal to 50 , if not 50 times, the need to increase the value $C_{g}$. When $n=25$, for the former case, when $C_{g} \geq 2.2$. As for the periodic verification testing apparatus with the above criteria has been reduced, it is only required to $C_{g} \geq 1.33$.

Of course, the value $C_{g}$ of the evaluation method is not limited to the geometry test equipment evaluation, other types of test equipment is also applicable.

It should be recognized that the above assessment indicators are quite demanding. After years of practice have been to relax the use of signs, mainly in August 1999 by the US and European ten car companies jointly issued the "measuring system capabilities" file. At this point the expression $C_{g}$ from to read:

$$
C_{g}=\frac{0.2 T}{4 s}
$$

It has been calculated and organize get to this condition $C_{g} \geq 2$ are substituted into the formula:

$$
\begin{aligned}
& 6 \mathrm{gs} \leq 10 \% \mathrm{~g} T \\
& 4 \mathrm{gs} \leq 10 \% \mathrm{~g} T
\end{aligned}
$$

The meaning of the above two equations expressed very clear: to be assessed on a detection result of the detection device being measured random error distribution width (ie confidence interval size), not more than one tenth tolerances measured. Formula showed confidence probability at this time was $99.37 \%$, while confidence probability formula under the conditions of $95 \%$. This is the true meaning of the measurement capability index $C_{g}$, its essence lies in this. 


\section{The Actual Measurement Results Analysis}

According to the above for the definition and analysis, the use of the integrated measuring instrument camshaft journal of the actual parameters of the repeated measurements of 50 times, the resulting based on the measured value and style as shown in Table 2 .

According to the standard required for a car company, the nominal value of each parameter needs camshaft and upper and lower limits are shown in Table 1.

Table 1 nominal value and the upper and lower measurement parameters

\begin{tabular}{l|c|l|l}
\hline Paremeters & Nominal value & $\begin{array}{l}\text { Uppe } \\
\text { r limit }\end{array}$ & $\begin{array}{l}\text { Lower } \\
\text { limit }\end{array}$ \\
\hline B journal diameter Left $/ \mathrm{mm}$ & 28.5 & 28.48 & 28.459 \\
\hline Right B journal diameter / mm & 28.5 & 28.48 & 28.459 \\
\hline B journal roundness / mm & 0 & 0.005 & 0 \\
\hline B journal taper / mm & 0 & 0.008 & 0 \\
\hline B for AE journal beating / mm & 0 & 0.02 & 0 \\
\hline
\end{tabular}

Therefore, the camshaft journal diameter tolerance: $T_{D}=0.021$

Camshaft journal taper tolerance: $T_{C}=0.008$

Camshaft journal roundness tolerance: $T_{R D}=0.005$

Camshaft journal runout tolerance: $T_{\Delta}=0.02$

Table 2 Experimental data in using the integrated measuring instrument developed camshaft measured

\begin{tabular}{|c|c|c|c|c|c|}
\hline $\begin{array}{l}\text { measuring } \\
\text { frequency }\end{array}$ & $\begin{array}{l}\text { B journal } \\
\text { taper / mm }\end{array}$ & $\begin{array}{l}\text { B journal } \\
\text { roundness } \\
\mathrm{mm}\end{array}$ & $\begin{array}{l}\text { Right B } \\
\text { journal } \\
\text { diameter / } \mathrm{mm}\end{array}$ & $\begin{array}{l}\text { B journal } \\
\text { diameter Left / } \\
\mathrm{mm}\end{array}$ & $\begin{array}{l}B \text { for } \mathrm{AE} \\
\text { journal } \\
\text { beating / } \mathrm{mm}\end{array}$ \\
\hline 1 & 0.0113 & 0.004 & 28.4721 & 28.4651 & 0.0086 \\
\hline 2 & 0.0112 & 0.0041 & 28.472 & 28.4652 & 0.0082 \\
\hline 3 & 0.0110 & 0.0042 & 28.4722 & 28.465 & 0.0078 \\
\hline 4 & 0.0112 & 0.0041 & 28.4721 & 28.4651 & 0.0088 \\
\hline 5 & 0.0111 & 0.0041 & 28.4721 & 28.4651 & 0.0088 \\
\hline 6 & 0.0108 & 0.004 & 28.4715 & 28.4657 & 0.0082 \\
\hline 7 & 0.0109 & 0.0038 & 28.4715 & 28.4656 & 0.0084 \\
\hline 8 & 0.0109 & 0.004 & 28.4717 & 28.4654 & 0.0083 \\
\hline 9 & 0.0108 & 0.004 & 28.4715 & 28.4656 & 0.008 \\
\hline 10 & 0.0111 & 0.0041 & 28.472 & 28.4651 & 0.0089 \\
\hline 11 & 0.0113 & 0.0041 & 28.4720 & 28.4651 & 0.0086 \\
\hline 12 & 0.0112 & 0.0041 & 28.470 & 28.4651 & 0.0084 \\
\hline
\end{tabular}




\begin{tabular}{|c|c|c|c|c|c|}
\hline $\begin{array}{l}\text { measuring } \\
\text { frequency }\end{array}$ & $\begin{array}{l}\text { B journal } \\
\text { taper / mm }\end{array}$ & $\begin{array}{l}\text { B journal } \\
\text { roundness } \\
\mathrm{mm}\end{array}$ & $\begin{array}{l}\text { Right } \quad \text { B } \\
\text { journal } \\
\text { diameter / mm }\end{array}$ & $\begin{array}{l}\text { B journal } \\
\text { diameter Left / } \\
\mathrm{mm}\end{array}$ & $\begin{array}{l}\mathrm{B} \text { for } \mathrm{AE} \\
\text { journal } \\
\text { beating } / \mathrm{mm}\end{array}$ \\
\hline 13 & 0.0110 & 0.0040 & 28.4722 & 28.4650 & 0.0080 \\
\hline 14 & 0.0112 & 0.0041 & 28.4721 & 28.4651 & 0.0088 \\
\hline 15 & 0.0111 & 0.0041 & 28.4721 & 28.4651 & 0.0088 \\
\hline 16 & 0.0108 & 0.0039 & 28.4718 & 28.4659 & 0.0086 \\
\hline 17 & 0.0109 & 0.004 & 28.4719 & 28.4658 & 0.0084 \\
\hline 18 & 0.0110 & 0.004 & 28.4717 & 28.4659 & 0.0085 \\
\hline 19 & 0.0108 & 0.004 & 28.4715 & 28.4656 & 0.0083 \\
\hline 20 & 0.0111 & 0.0041 & 28.472 & 28.4651 & 0.0089 \\
\hline 21 & 0.0113 & 0.004 & 28.4721 & 28.4653 & 0.0086 \\
\hline 22 & 0.0113 & 0.0041 & 28.4722 & 28.4656 & 0.0082 \\
\hline 23 & 0.0114 & 0.0042 & 28.4722 & 28.465 & 0.0078 \\
\hline 24 & 0.0112 & 0.0041 & 28.4721 & 28.4651 & 0.0086 \\
\hline 25 & 0.0111 & 0.0041 & 28.4721 & 28.4651 & 0.0088 \\
\hline 26 & 0.0108 & 0.004 & 28.4715 & 28.4657 & 0.0082 \\
\hline 27 & 0.0110 & 0.0038 & 28.4715 & 28.4656 & 0.0084 \\
\hline 28 & 0.0109 & 0.004 & 28.4717 & 28.4654 & 0.0083 \\
\hline 29 & 0.0110 & 0.004 & 28.4715 & 28.4656 & 0.008 \\
\hline 30 & 0.0111 & 0.0041 & 28.472 & 28.4651 & 0.0089 \\
\hline 31 & 0.0113 & 0.004 & 28.4721 & 28.4651 & 0.0086 \\
\hline 32 & 0.0110 & 0.0041 & 28.472 & 28.4652 & 0.0082 \\
\hline 33 & 0.0113 & 0.0042 & 28.4722 & 28.465 & 0.0078 \\
\hline 34 & 0.0112 & 0.0041 & 28.4721 & 28.4651 & 0.0088 \\
\hline 35 & 0.0112 & 0.0041 & 28.4721 & 28.4651 & 0.0086 \\
\hline 36 & 0.0108 & 0.004 & 28.4715 & 28.4657 & 0.0082 \\
\hline 37 & 0.0110 & 0.0038 & 28.4715 & 28.4656 & 0.0084 \\
\hline 38 & 0.0109 & 0.004 & 28.4717 & 28.4654 & 0.0083 \\
\hline 39 & 0.0108 & 0.004 & 28.4715 & 28.4656 & 0.008 \\
\hline 40 & 0.0111 & 0.0041 & 28.472 & 28.4651 & 0.0089 \\
\hline 41 & 0.0113 & 0.004 & 28.4721 & 28.4651 & 0.0086 \\
\hline 42 & 0.0112 & 0.0041 & 28.472 & 28.4652 & 0.0082 \\
\hline 43 & 0.0113 & 0.0042 & 28.4722 & 28.465 & 0.0078 \\
\hline 44 & 0.0112 & 0.0041 & 28.4721 & 28.4651 & 0.0088 \\
\hline 45 & 0.0111 & 0.0041 & 28.4721 & 28.4651 & 0.0088 \\
\hline
\end{tabular}




\begin{tabular}{|c|c|c|c|c|c|}
\hline $\begin{array}{l}\text { measuring } \\
\text { frequency }\end{array}$ & $\begin{array}{l}\text { B journal } \\
\text { taper } / \mathrm{mm}\end{array}$ & $\begin{array}{l}\text { B journal } \\
\text { roundness } \\
\mathrm{mm}\end{array}$ & $\begin{array}{l}\text { Right B } \\
\text { journal } \\
\text { diameter / } \mathrm{mm}\end{array}$ & $\begin{array}{l}\text { B journal } \\
\text { diameter Left / } \\
\mathrm{mm}\end{array}$ & $\begin{array}{l}\mathrm{B} \text { for } \mathrm{AE} \\
\text { journal } \\
\text { beating / } \mathrm{mm}\end{array}$ \\
\hline 46 & 0.0108 & 0.004 & 28.4715 & 28.4657 & 0.0082 \\
\hline 47 & 0.0109 & 0.0038 & 28.4715 & 28.4656 & 0.0084 \\
\hline 48 & 0.0109 & 0.004 & 28.4717 & 28.4654 & 0.0083 \\
\hline 49 & 0.0108 & 0.004 & 28.4715 & 28.4656 & 0.008 \\
\hline 50 & 0.0111 & 0.0041 & 28.472 & 28.4651 & 0.0089 \\
\hline$C_{0}$ & 2.2271 & 2.5801 & 2.7889 & 3.7634 & 2.9976 \\
\hline $\begin{array}{l}\text { average } \\
\text { value }\end{array}$ & 0.01106 & 0.00404 & 28.471846 & 28.465318 & 0.008418 \\
\hline $\begin{array}{l}\text { Standard } \\
\text { deviation }\end{array}$ & $96^{0.00017}$ & $9.689 \mathrm{E}-05$ & 0.0003765 & 0.000279 & 0.0003336 \\
\hline
\end{tabular}

According to the actual measurement data camshaft observed 50 times the diameter of the test results in a journal, roundness, taper, and beating and other measurement parameters, you can see, the dispersion is small, the standard diameter of the test results is less than 0.0003 , round the standard deviation of the test results is less than 0.0002 , the standard deviation is less than 0.0002 taper test results, standard deviation jitter test results is less than 0.0004 , repeated measurement error of each parameter can be controlled within $C_{g} \geq 2$, has good stability and repeatability, reach the design goal.

\section{Conclusion}

This paper introduces the measuring instrument alignment, measurement data were analyzed by the experimental test data in accordance with the measurement capability index $C_{g}$ assessment repetitive detection system. The results of multiple measurements of the workpiece measuring instrument to verify the accuracy of measuring compliance with the requirements that it has good reliability and stability

\section{Refences}

[1] Zhu Zhengde. Measurement Capability Index Cp- A Generic Detection Assessment Indicators. Aviation Precision Manufacturing Technology .2001.6.

[2] Wang Wuyi, Xu Dingjie, Chen Jianyi. Error Theory and Data Processing. Harbin Institute of Technology Press, 2001.10. 